DOT/FAA/AM-12/13

Office of Aerospace Medicine

Washington, DC 20591

\title{
In Vitro Absorption of Atmospheric Carbon Monoxide and Hydrogen Cyanide in Undisturbed Pooled Blood
}

Tiffany M. Thoren

University of Central Oklahoma

Edmond, OK 73034

Kristi S. Thompson

Cherokee Nation Distributors

Garden Ridge, TX 78266

Patrick S. Cardona

Arvind K. Chaturvedi

Dennis V. Canfield

Civil Aerospace Medical Institute

Federal Aviation Administration

Oklahoma City, OK 73125

September 2012

Final Report 


\section{NOTICE}

This document is disseminated under the sponsorship of the U.S. Department of Transportation in the interest of information exchange. The United States Government assumes no liability for the contents thereof.

This publication and all Office of Aerospace Medicine technical reports are available in full-text from the Civil Aerospace Medical Institute's publications Web site:

www.faa.gov/go/oamtechreports 
Technical Report Documentation Page

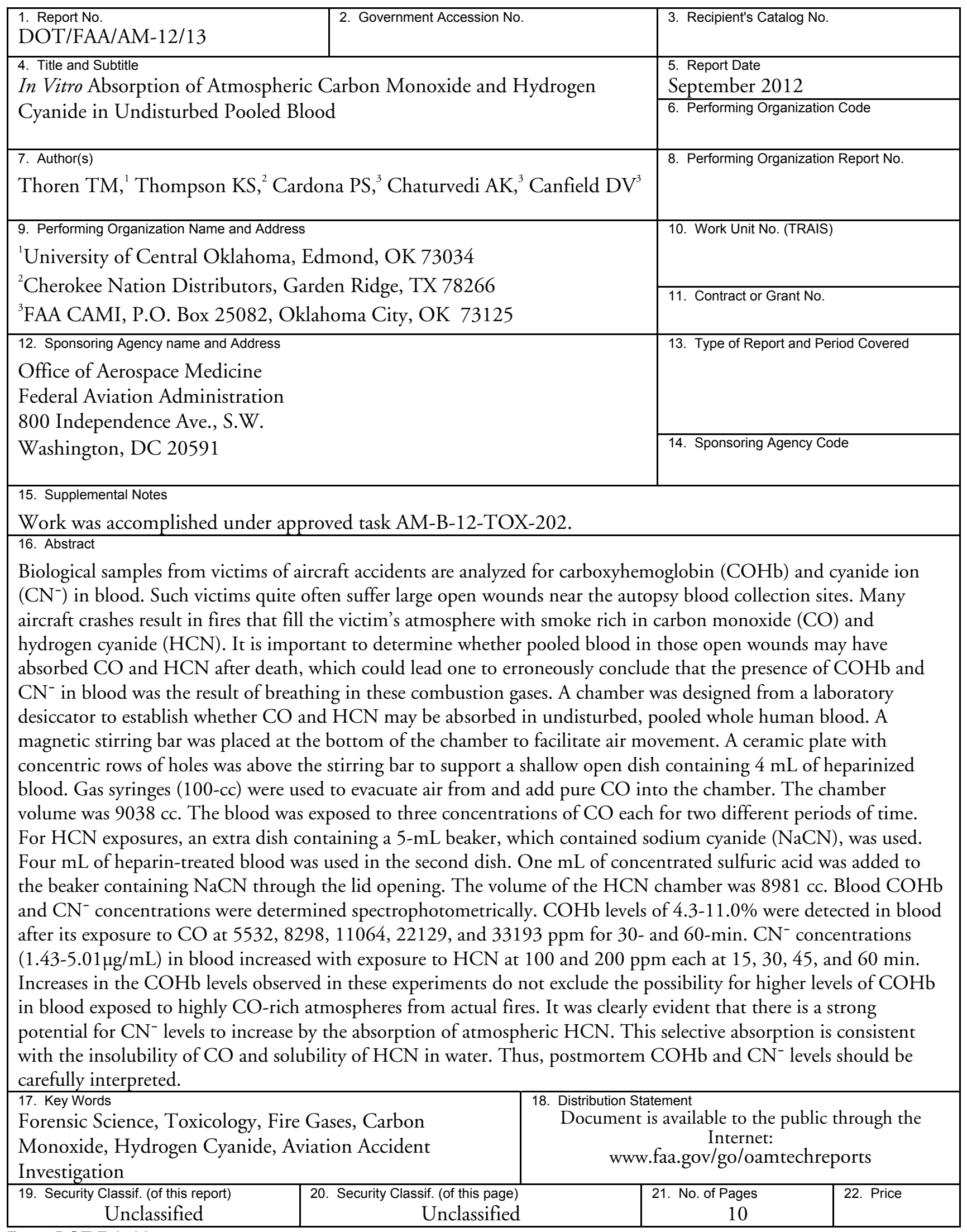

Form DOT F 1700.7 (8-72)

Reproduction of completed page authorized 



\section{CONTENTS}

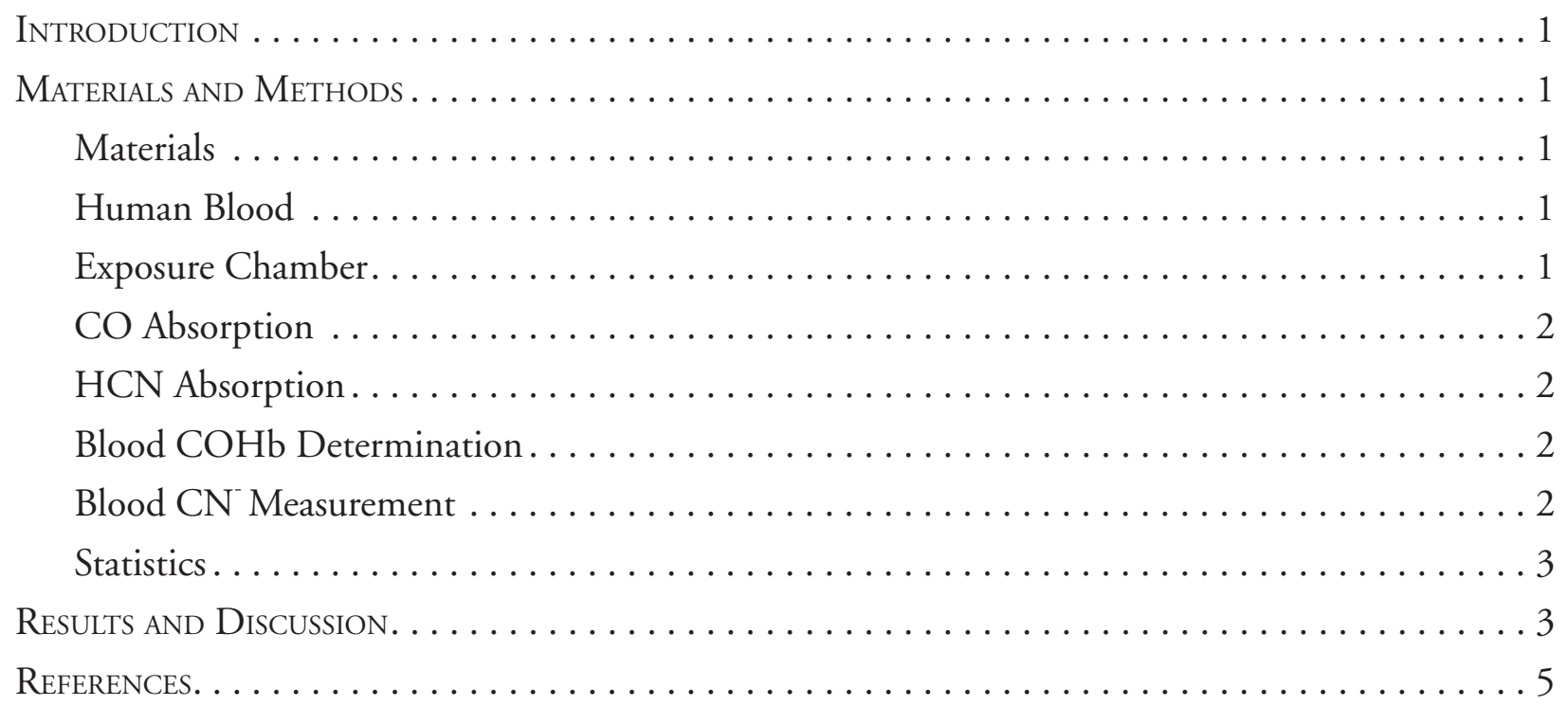





\section{In Vitro Absorption of Atmospheric Carbon Monoxide and Hydrogen Cyanide in Undisturbed Pooled Blood}

\section{INTRODUCTION}

The Federal Aviation Administration's (FAA's) Civil Aerospace Medical Institute (CAMI; Oklahoma City, OK) assists in the investigation of fatal aircraft accidents by conducting toxicological analyses of biological specimens collected from the victims of the accidents $(1,7)$. These biological samples are submitted by the local pathologists to CAMI in coordination with the FAA's Office of Accident Investigation and Prevention and authorized by the National Transportation Safety Board (NTSB). The NTSB investigates aviation accidents that occur within the jurisdiction of the United States.

One aspect of the toxicological analyses is the determination for the presence of primary combustion gases in blood specimens. Combined with the crash site investigation, autopsy and pathology findings, and toxicology results, the investigators could determine whether the crewmembers were incapacitated by engine carbon monoxide (CO) leaks into the cabin area, whether they survived the crash and were overcome by inhaling $\mathrm{CO}$ and hydrogen cyanide (HCN) from aircraft fires, whether the victims died on impact, or they came to a rapid death from the intense heat of the fire, without inhaling these gases.

Because of the violent impacts involved in crashes, victims quite often suffer large open wounds near sites on the body from where autopsy whole blood is collected. Many aircraft crashes result in fire, which, in turn, fill the atmosphere around the victims with $\mathrm{CO}$ and $\mathrm{HCN}$ laden smoke. Therefore, it is important to determine whether pooled blood in those open wounds may have absorbed $\mathrm{CO}$ and HCN present in the atmosphere after death and could lead investigators to erroneously conclude that the presence of carboxyhemoglobin $(\mathrm{COHb})$ and cyanide ion $\left(\mathrm{CN}^{-}\right)$in whole blood was the result of breathing in primary combustion gases. For this, an in vitro study was conducted to evaluate the absorption of these fire gases in undisturbed pooled human blood.

\section{MATERIALS AND METHODS}

\section{Materials}

All reagents, chemicals, and solvents were of analytical grade and were of the highest available purity. Aforementioned items, standards, and other laboratory supplies were obtained from commercial sources. CO of $>99 \%$ purity was obtained in a compressed gas cylinder from Airgas (Oklahoma City, OK).

\section{Human Blood}

Blood samples were collected from healthy volunteers. The human subject participation was approved by the CAMI Institutional Review Board. The subjects were not on any medication and were non-smokers. Blood was collected in $10-\mathrm{ml}$ green-top glass tubes at the CAMI Clinic. These tubes were sterile and contained sodium heparin. The collected blood was stored at $0-4^{\circ} \mathrm{C}$. Prior to the absorption experiments, the collected blood was brought to the room temperature and was mixed by slowly inverting the blood tubes several times.

\section{Exposure Chamber}

A large glass vacuum laboratory desiccator with a ceramic plate (platform) with concentric rows of holes was used as an exposure chamber. The plate was located in the center to horizontally partition the desiccator and served as a platform for placing a blood sample in an open glass stender dish ( $37 \mathrm{~mm}$ x $25 \mathrm{~mm}$; Carolina Biological Supply Company, Burlington, NC). Other items, including any liquid in a container, needed for the experiment were also placed on the platform. The tapered sleeve valve of the desiccator lid was configured with a female Luer-Lok fitting affixed with a small section of Tygon ${ }^{\circledR}$ tubing. Air was evacuated and $\mathrm{CO}$ was added to the chamber by using 100-cc valved gas-tight syringes with male Luer-Lok fittings (Precision Sampling Corporation, Baton Rouge, LA) through the tapered sleeve valve. A minimal amount of silicone-based vacuum grease was used on the tapered sleeve valve, on the rims of the lid, and on the body of the desiccator. To mix and circulate the atmospheric gases within the chamber, a large cross-shaped Teflon-coated magnetic stirring bar was placed inside the chamber at the bottom. The desiccator assembly was placed on a magnetic stirring plate. The rotation of the magnetic bar was controlled by adjusting the knob of the stirring plate. Each experiment was performed with a $4-\mathrm{mL}$ aliquot of blood in an open glass stender dish. All experiments were performed in triplicate at laboratory temperature in a fume hood (Hamilton Industries, Two Rivers, WI). After having been exposed to $\mathrm{CO}$ or $\mathrm{HCN}$, the blood samples were refrigerated $\left(0-4^{\circ} \mathrm{C}\right)$. They were then analyzed for $\mathrm{COHb}$ or $\mathrm{CN}^{-}$in accordance with standard CAMI laboratory analytical procedures. 


\section{CO Absorption}

Total volume of the chamber with the ceramic plate, stirring bar, and dish, including the water equivalent of $4 \mathrm{~mL}$ blood sample, was determined by measuring the volume of water necessary to fill the desiccator and its lid. The chamber volume was found to be $9.038 \mathrm{~L}$. A $\mathrm{CO}$ gas cylinder with a pressure regulator was configured with a valve having a female Luer-Lok fitting affixed with a small piece of Tygon ${ }^{\circledR}$ tubing. After placing the magnetic stirring bar in the bottom and $4 \mathrm{~mL}$ human blood sample in an open stender dish on the ceramic plate in the desiccator, it was sealed with the lid. Measured volumes of air were removed from the chamber through the tapered sleeve valve and were replaced with the equivalent volumes of $\mathrm{CO}$ to reach the desired atmospheric concentrations of CO in the chamber. The removal of air and its replacement with $\mathrm{CO}$ was achieved by using the gastight syringe. After adding $\mathrm{CO}$, the tapered sleeve valve was closed. Various volumes of CO corresponding to its atmospheric concentrations in the chamber are given in Table I. The undisturbed human blood samples in the dishes were exposed to the circulated $\mathrm{CO}$ atmosphere for 30 and $60 \mathrm{~min}$. After the exposure period for each experiment, the chamber was carefully opened by sliding the lid, and the blood sample was transferred in three 0.5$\mathrm{mL}$ screw-capped polypropylene tubes (Fisher Scientific, Pittsburgh, PA) for COHb analysis. These blood aliquots were refrigerated until analyzed.

\section{HCN Absorption}

The exposure apparatus was further modified for conducting HCN absorption experiments by using an open glass dish containing a 5 -mL glass beaker having a weighed amount of sodium cyanide $(\mathrm{NaCN})$. The ideal gas law was used to calculate the amount of the limiting reactant (i.e., $\mathrm{NaCN}$ ) needed to react with sulphuric acid to achieve the required concentrations of $\mathrm{HCN}$ in the chamber. By water displacement, the volume of the chamber for $\mathrm{HCN}$ experiments was determined to be $8.981 \mathrm{~L}$, after taking into account the volumes of the blood sample, sulfuric acid, and the items used in the desiccator. To conduct the experiment, $4 \mathrm{~mL}$ of blood was used in a stender dish. With the lid of the chamber partially opened, $1 \mathrm{~mL}$ of concentrated sulfuric acid was added to the beaker containing $\mathrm{NaCN}$; then, the chamber lid was immediately closed. The tapered sleeve valve on the lid was in the closed position. The amount of $\mathrm{NaCN}$ in relation to sulfuric acid corresponded to an equivalent molar proportion to produce the desired amount of $\mathrm{HCN}$ $\left(\mathrm{H}_{2} \mathrm{SO}_{4}+2 \mathrm{NaCN} \rightarrow 2 \mathrm{HCN}+\mathrm{Na}_{2} \mathrm{SO}_{4}\right)$. Using the gas law, the calculated final exposure concentrations of $\mathrm{HCN}$ in the chamber at the normal temperature and pressure were 100 and $200 \mathrm{ppm}(\mu \mathrm{L} / \mathrm{L})$. The HCN exposure time to the undisturbed pooled blood samples ranged from 15 to $60 \mathrm{~min}$. After the exposure time, the chamber was carefully opened by sliding the lid, and the blood was transferred in three $1.5-\mathrm{mL}$ screw-capped polypropylene tubes (Fisher Scientific, Pittsburgh, PA) for $\mathrm{CN}^{-}$analysis.

\section{Blood COHb Determination}

Blood $\mathrm{COHb}$ concentrations in the specimens were determined spectrophotometrically $(4,5,23,25)$. Blood cells were hemolyzed with ammonium hydroxide, and the hemolysate was treated with sodium dithionite to reduce methemoglobin and oxyhemoglobin to deoxyhemoglobin $(\mathrm{HHb})$. The blood solution obtained was scanned in the visible range from $450 \mathrm{~nm}$ to $750 \mathrm{~nm}$. The absorbance of the blood solution was recorded at $540 \mathrm{~nm}$, a wavelength of maximum absorbance for $\mathrm{COHb}$, and at $579 \mathrm{~nm}$, a wavelength at which the spectra of various species of $\mathrm{HHb}$ have the same absorbance (isosbestic point). Ratios of the absorbance values of the specimens at these two wavelengths were used to determine $\% \mathrm{COHb}$ in the specimen by using a mathematical equation in relation to a positive $\mathrm{COHb}$ control prepared in human blood by using $\mathrm{CO}(4,5)$.

\section{Blood CN Measurement}

HCN was liberated from the blood sample by acidification and microdiffusion, trapped in a dilute alkaline solution, and converted to cyanogen chloride after reacting with chloramine-T. Subsequently, cyanogen

Table I. Various Volumes of CO Corresponding to the Final Atmospheric Concentrations of the Gas in the Exposure Chamber

\begin{tabular}{cc}
\hline $\begin{array}{c}\text { Volumes of CO Inserted } \\
\text { in Chamber } \\
(\mathrm{cc} ; \mathrm{mL})\end{array}$ & $\begin{array}{c}\text { Final Concentration of CO in } \\
\text { Exposure Chamber } \\
(\mathrm{ppm} ; \mu \mathrm{L} / \mathrm{L})\end{array}$ \\
\hline 50 & 5532 \\
75 & 8298 \\
100 & 11064 \\
200 & 22129 \\
300 & 33193 \\
\hline
\end{tabular}


chloride was allowed to react with pyridine to form $\mathrm{N}$ cyanopyridinium chloride, followed by a reaction wherein $N$-cyanopyridinium chloride was cleaved to form an anil of glutaconic aldehyde. This aldehyde then coupled with barbituric acid to a red-pinkish, highly resonant product $(3,10,21)$. Appearance of a red-pinkish product suggested the presence of $\mathrm{CN}^{-}$. The level of $\mathrm{CN}^{-}$was quantitatively determined by measuring the absorbance of the product at $580 \mathrm{~nm}$. Along with blood samples, a $\mathrm{CN}^{-}$-free human blood sample and $2 \mu \mathrm{g} / \mathrm{mL} \mathrm{CN}^{-}$control in human blood were also processed and analyzed. The absorbance of each solution at $580 \mathrm{~nm}$ against the solution obtained by processing water, as described above, was measured as soon as possible, since the color product produced is not very stable.

\section{Statistics}

The mean and standard deviation (SD) of quantitative analytical values for each analyte were calculated by using Microsoft ${ }^{\circledR}$ Office Excel 2003 (Redmond, WA). Significance of differences between means of observations was checked by Student's $t$-test. The difference between two means was considered significant, with $p<0.05$.

\section{RESULTS AND DISCUSSION}

Under the experimental conditions, an increase of only a small amount of $\mathrm{COHb}$ was detected in the undisturbed whole blood after its exposure to $\mathrm{CO}$ at $5532,8298,11064,22129$, and 33193 ppm for 30 and $60 \mathrm{~min}$. The $\mathrm{COHb}$ concentration in the blood was found to be $2.8 \%$ at no added atmospheric $\mathrm{CO}$ concentration, whereas the $\mathrm{COHb}$ levels ranged from 4.3 to $11.0 \%$ with $5532-33193$ ppm CO. Except for the $11.0 \% \mathrm{COHb}$ observed with $33193 \mathrm{ppm} \mathrm{CO}$ for the 60-min exposure, all other $\mathrm{COHb}$ values were below the laboratory cutoff of $10 \%$ (Fig. 1). The $11.0 \%$ $\mathrm{COHb}$ value was not statistically significant $(p=0.07)$ with the closest corresponding 60-min $\mathrm{COHb}$ value of $8.6 \%$ at $22129 \mathrm{ppm}$ CO. The highest level of $11.0 \%$ $\mathrm{COHb}$ observed under the experimental conditions was barely above the laboratory cutoff. COHb at $10 \%$ is considered asymptomatic in humans $(13,15)$, but tightness in forehead, possible slight headache, and dilation of cutaneous blood vessels are linked with $10-20 \% \mathrm{COHb}(13,15)$. Normally, healthy individuals may accumulate up to $10 \% \mathrm{COHb}$ from inhaling air contaminated with CO $(2,24)$ - for example, from smoking, breathing gasoline exhaust fume rich air, or operating (travelling in) vehicles with faulty exhaust systems.

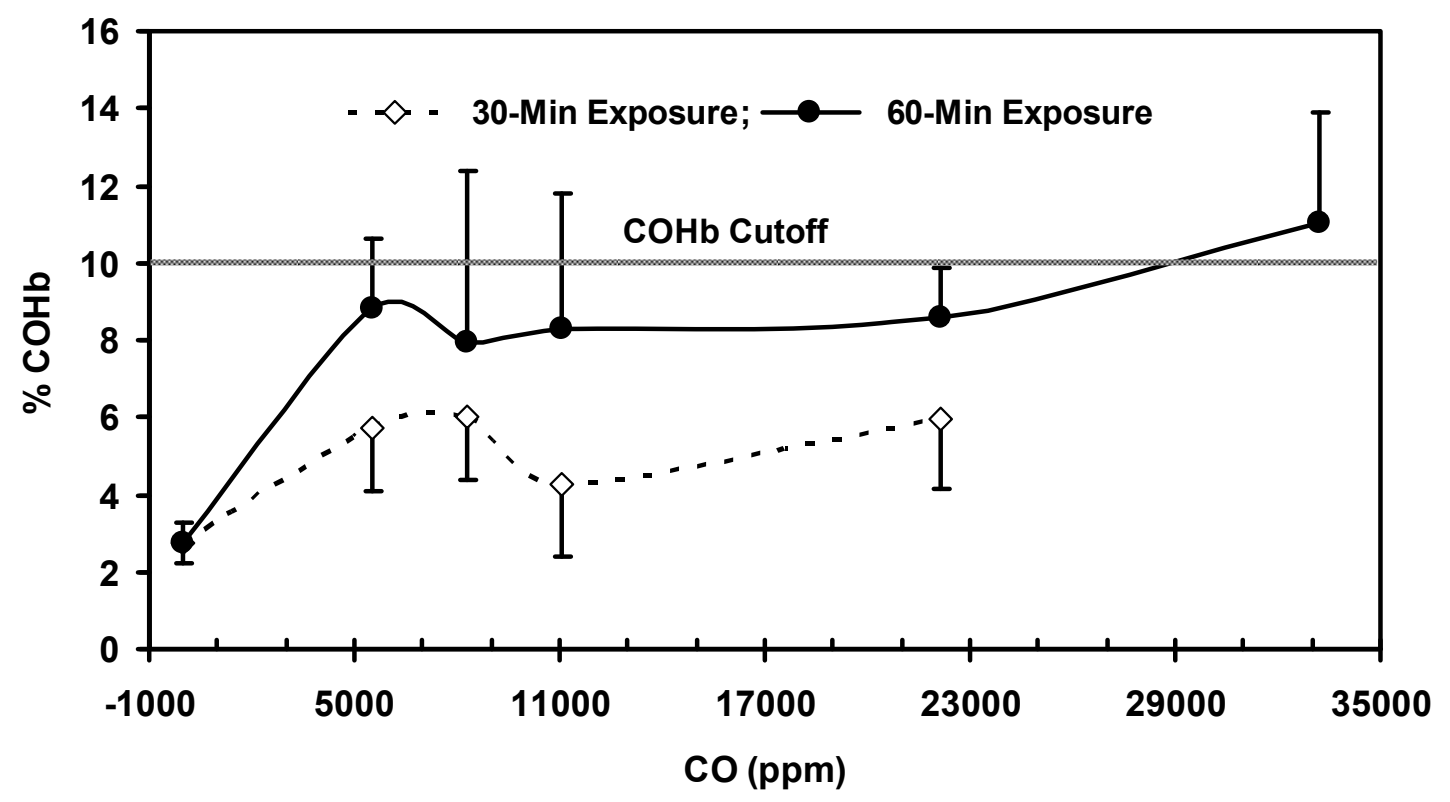

Figure 1. Passive absorption of $\mathrm{CO}$ at various atmospheric concentrations in undistributed pooled whole blood samples. The exposure times of the blood samples to CO were 30 and 60 min. The analytical cutoff value of the CAMI laboratory for reporting the $\mathrm{COHb}$ value is $10 \%$ and is shown in the figure by a horizontal line. Vertical lines shown in the curves are error bars. The details of the experimental design and analytical methods are given in the Materials and Methods section. 


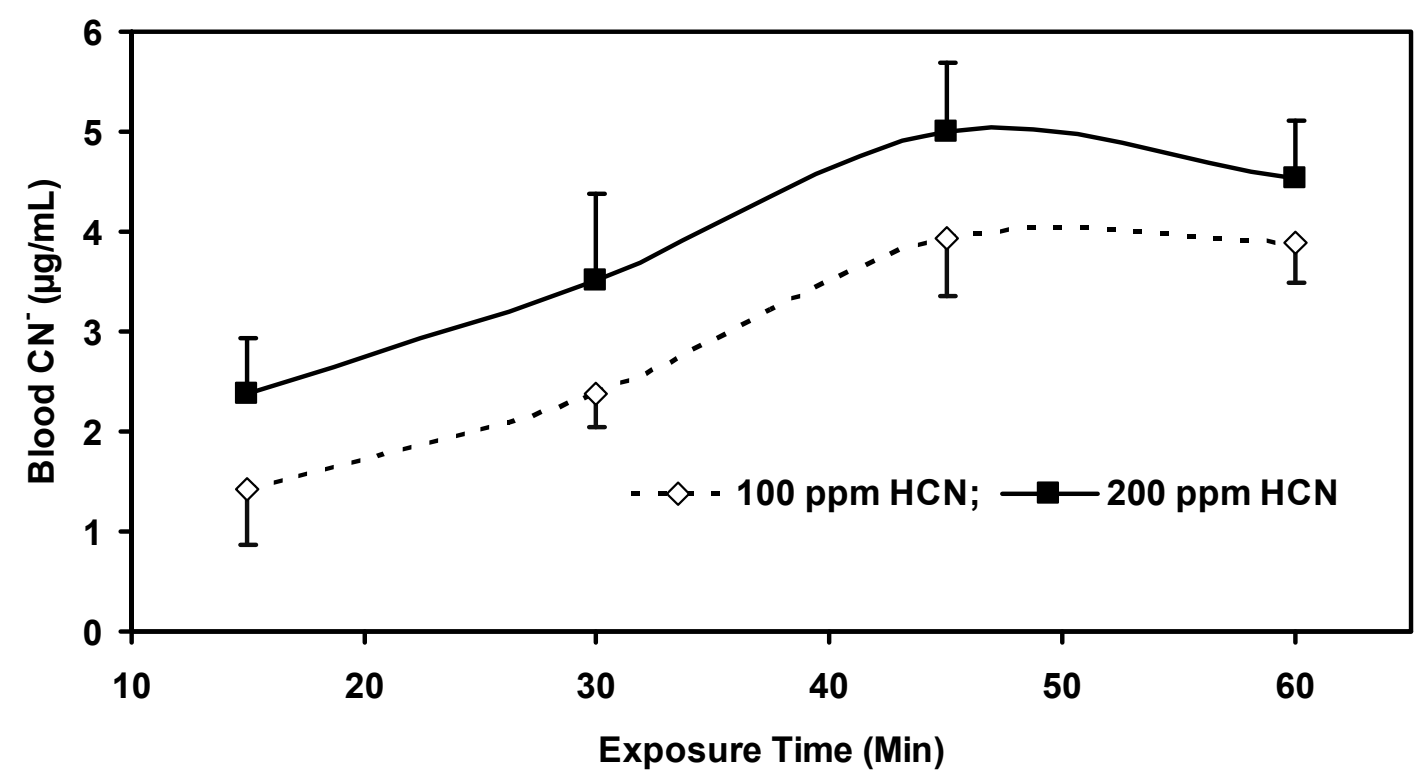

Figure 2. Passive uptake of $\mathrm{HCN}$ at 100 and 200 ppm atmospheric concentrations in undisturbed pooled whole blood samples. The exposure times of the blood samples to HCN at each atmospheric concentration were 15, 30, 45, and $60 \mathrm{~min}$. Vertical lines shown in the curves are error bars. The analytical cutoff value of the CAMI laboratory for reporting the $\mathrm{CN}^{-}$value is $0.25 \mu \mathrm{g} / \mathrm{mL}$. The details of the experimental design and analytical methods are given in the Materials and Methods section.

Contrary to the $\mathrm{COHb}$ findings, $\mathrm{CN}^{-}$concentrations in whole blood increased with exposure to an atmosphere containing $\mathrm{HCN}$ at 100 and $200 \mathrm{ppm}$ each for $15,30,45$, and $60 \mathrm{~min}$. The $\mathrm{CN}^{-}$concentration in blood ranged from 1.43 to $5.01 \mu \mathrm{g} / \mathrm{mL}$. In humans, $\mathrm{CN}^{-}$ levels from 1.0 to $\geq 2.5 \mu \mathrm{g} / \mathrm{mL}$ could cause moderateto-severe toxicity, producing mydriasis, cyanosis, and death $(13,15)$. Under the experimental conditions, no $\mathrm{CN}^{-}$was analytically detected in the blood sample not exposed to HCN. As depicted in Figure 2, the passive uptake of $\mathrm{HCN}$ increased with a function of HCN concentration and exposure time. The 15-min $\mathrm{CN}^{-}$values of 100 and 200 ppm exposures were different from each other $(p<0.05)$. Similarly, the 30-, 45-, and 60-min values of 100 and of 200 ppm HCN were respectively different from the corresponding time point values. After the 45-min exposure, the $\mathrm{CN}^{-}$ concentration plateaued or even became less. The $\mathrm{CN}^{-}$ concentrations for $100 \mathrm{ppm} \mathrm{HCN}$ were significantly different $(p<0.05)$ with 15 -min versus 30 -min values and 30 -min versus 45 -min values, but the values at 45 min and 60 min were not significant $(p=0.90)$. With 200 ppm HCN experiments, the $\mathrm{CN}^{-}$concentration also significantly increased up to $45 \mathrm{~min}(p<0.05)$; although the $\mathrm{CN}^{-}$values at $45 \mathrm{~min}$ and $60 \mathrm{~min}$ were significantly different from each other $(p<0.05)$, there was a decrease at $60 \mathrm{~min}$ instead of an increase. In relation to the $45-\mathrm{min} \mathrm{CN}^{-}$concentration, the 60-min value was $9 \%$ less $(p=0.034)$. Such a decrease in the blood $\mathrm{CN}^{-}$value might be related to a saturation of the HCN uptake system of the blood and a possible conversion of the absorbed $\mathrm{HCN}$ into some other chemical form(s) such as thiocyanate (13). That type of conversion may lead to the unaccountability for the total absorbed $\mathrm{HCN}$, as all $\mathrm{CN}^{-}$may not be available for the analytical reaction.

It is a known fact that each fire is different. Types and amounts of combustion products generated during fires can vary from fire to fire $(6,11,20,22)$. Such variations depend upon the physical and chemical characteristics and amounts of the burning material and environmental conditions; for example, heat and air supply. In air transport cabin mockup fire experiments, consisting of passenger seats, urethane seat foam, and other materials under different burning conditions, $\mathrm{CO}$ has been recorded to be present in concentrations ranging from < $0.1 \%(1000 \mathrm{ppm})$ to $>1.5 \%(15000 \mathrm{ppm})(18)$. In this 1970 study, HCN (10 ppm) was reported to be present in only one fire experiment. CO concentrations up to $14 \%$ (140000 ppm) and $\mathrm{HCN}$ up to $1721 \mathrm{ppm}$ have been reported in different combustion experiment atmospheres $(8,9,12,14,16,17,19)$. The CO (5532-33193 ppm) and $\mathrm{HCN}$ (100 and $200 \mathrm{ppm}$ ) concentrations used in the present in vitro study fall within the concentration ranges of these gases reported in the experimental fire atmospheres.

Although findings of the present study demonstrated that the $\mathrm{COHb}$ level in the undisturbed pooled blood exposed to an atmosphere containing $\mathrm{CO}$ within the 
parameters of this experiment would increase only up to $11 \%$, it does not necessarily exclude the possibility that the $\mathrm{COHb}$ level in pooled blood from an actual fire victim may be higher than $11 \%$ if that blood were exposed to a very high concentration of atmospheric $\mathrm{CO}$ from an actual fire. Such $\mathrm{COHb}$ increase would occur because of the high concentration-gradient between blood and $\mathrm{CO}$-rich air. Increase in the $\mathrm{COHb}$ level would also be possible if the pooled blood were disturbed, thereby producing a larger dynamic exposure surface area. With $\mathrm{HCN}$, however, there is a strong clear-cut evidence that $\mathrm{CN}^{-}$levels would easily increase in the undisturbed pooled blood due to the absorption of atmospheric $\mathrm{HCN}$ present in the fire environment.

This selective absorption pattern of the two primary combustion gases is consistent with the insolubility of $\mathrm{CO}$ and solubility of $\mathrm{HCN}$ in water, thus in the whole blood. The present study suggests that the blood $\mathrm{COHb}$ and $\mathrm{CN}^{-}$levels found in the postmortem samples collected from the victims of fire accidents should be carefully interpreted in view of the potential for the selective presence of these primary combustion gases being absorbed in pooled blood after death.

\section{REFERENCES}

1. Aviation Safety Research Act of 1988: Public Law 100-591 [H.R. 4686]. 100th U.S. Cong., 2nd Sess., 102 Stat. 3011 (03 November 1988).

2. Baselt RC, ed. Disposition of Toxic Drugs and Chemicals in Man. 7th ed. Foster City, CA: Biomedical Publications; 2004:175-8.

3. Blanke RV. Analysis of drugs and toxic substances. In: Tietz NW, ed. Fundamentals of Clinical Chemistry. 2nd ed. Philadelphia, PA: W.B. Saunders Co.; 1976:1116-8.

4. Canfield DV, Smith M, Ritter RM, Chaturvedi AK. Preparation of carboxyhemoglobin standards and calculation of spectrophotometric quantitation constants. J Forensic Sci 1999; 44(2):409-12.

5. Canfield DV, Smith MD, Ritter RM, Chaturvedi AK. Preparation of carboxyhemoglobin standards and calculation of spectrophotometric quantitation constants. Washington, DC: U.S. Department of Transportation, Federal Aviation Administration, Office of Aviation Medicine; 1998 Aug. Report No.: DOT/FAA/AM-98/21.
6. Chaturvedi AK. Smoke! Oklahoma City, OK: U.S. Department of Transportation, Federal Aviation Administration, Civil Aeromedical Institute, Aeromedical Education Division. Report No.: AM-400-95/1.

7. Chaturvedi AK, Smith DR, Soper JW, Canfield DV, Whinnery JE. Characteristics and toxicological processing of postmortem pilot specimens from fatal civil aviation accidents. Aviat Space Environ Med 2003; 74(3):252-9.

8. Endecott BR, Sanders DC, Chaturvedi AK. Simultaneous gas-chromatographic determination of four toxic gases generally present in combustion atmospheres. Washington, DC: U. S. Department of Transportation, Federal Aviation Administration, Office of Aviation Medicine; 1994 Sep. Report No.: DOT/FAA/AM-94/18.

9. Endecott BR, Sanders DC, Chaturvedi AK. Simultaneous gas chromatographic determination of four toxic gases generally present in combustion atmospheres. J Anal Toxicol 1996; 20(3):189-94.

10. Feldstein M, Klendshoj NC. The determination of volatile substances by microdiffusion analysis. J Forensic Sci 1957; 2:39-58.

11. Gad SC. The toxicity of smoke and combustion gases. In: Gad SC, Anderson RC, eds. Combustion Toxicology. Boca Raton, FL: CRC Press, Inc.; 1990:63-80.

12. Gad SC, Smith AC. Influence of heating rates on the toxicity of evolved combustion products: results and a system for research. In: Hartzell GE, ed. Advances in Combustion Toxicology, Vol. 1. Lancaster, PA: Technomic Publishing Co., Inc.; 1989:65-79.

13. Gossel TA, Bricker JD. Principles of Clinical Toxicology. 3rd ed. New York, NY: Raven Press; 1994:109-34.

14. Grand AF. Effect of experimental conditions on the evolution of combustion products using a modified University of Pittsburgh toxicity test apparatus. In: Hartzell GE, ed. Advances in Combustion Toxicology, Vol. 1. Lancaster, PA: Technomic Publishing Co., Inc.; 1989:298-322.

15. ISO International Standard. Analysis of blood for asphyxiant toxicants—carbon monoxide and hydrogen cyanide. Geneva, Switzerland: International Organization for Standardization (ISO); 15 Aug 2008. Report No.: First Edition; ISO 27368:2008 (E). 
16. Lattimer BY, Vandsburger U, Roby RJ. Carbon monoxide levels in structure fires: effects of wood in the upper layer of a post-flashover compartment fire. Fire Technology 1998; 34(4):325-55.

17. Levin BC, Braun E, Paabo M, Harris RH, Navarro M. Reduction of hydrogen cyanide concentrations and acute inhalation toxicity from flexible polyurethane foam combustion products by the addition of copper compounds. Part IV. Effects of combustion conditions and scaling on the generation of hydrogen cyanide and toxicity from flexible polyurethane foam with and without copper compounds. Gaithersburg, MD: U.S. Department of Commerce, National Institute of Standards and Technology (NIST); December 1992. Report No.: NISTIR 4989.

18. Marcy JF. Air transport cabin mockup fire experiments. Atlantic City, NJ: U.S. Department of Transportation, Federal Aviation Administration, National Aviation Facilities Experimental Center; December 1970. Report No.: FAA-RD-70-81.

19. Morikawa T, Yanai E. Toxic gases evolution from air-controlled fires in a semi-full scale room. In: Hartzell GE, ed. Advances in Combustion Toxicology, Vol. 2. Lancaster, PA: Technomic Publishing Co., Inc.; 1989:70-85.
20. Petajan JH, Voorhees KJ, Packham SC, Baldwin RC, Einhorn IN, Grunnet ML, et al. Extreme toxicity from combustion products of a fireretarded polyurethane foam. Science 1975; 187(4178):742-4.

21. Rieders F. Cyanide: type B procedure. In: Sunshine I, ed. Methodology for Analytical Toxicology, Vol. I; 5th Printing, 1987. Boca Raton, FL: CRC Press, Inc.; 1975:114-5.

22. Sanders DC, Endecott BR, Chaturvedi AK. Comparison of toxicity rankings of six aircraft cabin polymers by lethality and by incapacitation in rats. Aviat Space Environ Med 1992; 63(10):870-4.

23. Sanderson JH, Sotheran MF, Stattersfield JP. A new method of carboxyhaemoglobin determination. $\mathrm{Br}$ J Ind Med 1978; 35(1):67- 72.

24. Williams LA. Carbon Monoxide: type A procedure. In: Sunshine I, ed. Methodology for Analytical Toxicology, Vol. I; 5th Printing, 1987. Boca Raton, FL: CRC Press, Inc.; 1975:64-6.

25. Winek CL, Prex DM. A comparative study of analytical methods to determine postmortem changes in carbon monoxide concentration. Forensic Sci Int 1981; 18(2):181-7. 